\title{
Propuesta metodológica de evaluación del balance social en asociaciones de economía popular y solidaria del Ecuador
}

\author{
William Patricio Espín Maldonado \\ María Belén Bastidas Aráuz \\ Antonio Durán Pinos
}

RESUMEN: La economía popular y solidaria como modelo económico alternativo en el Ecuador se fundamenta en el artículo 283 de la Constitución Política del año 2008. La implementación de este modelo aún es nuevo y requiere de distintos aportes técnicos y metodológicos que promuevan el desarrollo de los sectores económicos agrupados en asociaciones, cooperativas, comunidades y unidades económicas populares. Conocer el impacto social y económico es fundamental para establecer políticas de fomento a estas formas de organización; en la economía tradicional existe diversidad de metodologías para analizar el impacto de un sector productivo, sin embargo, en la economía popular y solidaria existe un modelo de análisis del balance social al sistema Cooperativista Financiero propuesto por la SEPS mediante la definición de macro dimensiones y dimensiones, sin contar aún con una metodología que permita establecer el balance social en el sistema asociativo.

En la presente propuesta se desarrolla un modelo valorativo de análisis de balance social mediante el desarrollo y aplicación de indicadores que influyen las macro dimensiones y dimensiones establecidas por la Superintendencia, las cuales han sido adaptadas al sistema Asociativo con el propósito de analizar el impacto de este modelo económico solidario. Esta metodología entonces, se convierte en una herramienta práctica para que las asociaciones del sector económico popular y solidario evalúen el cumplimiento de los principios del modelo organizativo.

PALABRAS CLAVE: Balance Social, Economía popular y solidaria, Indicadores, Dimensión, Asociaciones.

CLAVES ECONLIT: A13, M14, M19, Z13.

Cómo citar este artículo / How to cite this article: ESPÍN, W.P., BASTIDAS, M.B. \& DURÁN, A. (2017):

"Propuesta metodológica de evaluación del balance social en asociaciones de economía popular y solidaria del Ecuador", CIRIEC-España, Revista de Economía Pública, Social y Cooperativa, 90, 123-157.

Correspondencia: William Patricio Espín Maldonado, Ecuador / Napo / Tena, Magister en Formulación, Evaluación y Gerencia de Proyectos para el Desarrollo; María Belén Bastidas Aráuz, Ecuador / Chimborazo / Riobamba, Docente Universitario, Escuela Superior Politécnica de Chimborazo / Facultad de Salud Pública, Magister en Planificación y Gestión de Proyectos Agroturístico y Ecológicos, y Antonio Durán Pinos, Ecuador / Chimborazo / Riobamba, Docente Universitario. Escuela Superior Politécnica de Chimborazo / Facultad de Administración de Empresas, Magister en Docencia Universitaria e Investigación Educativa. Contacto: pato_em@hotmail.com 


\title{
EXPANDED ABSTRACT
}

\section{Methodological Proposal for Social Balance Evaluation in Social and Solidarity-Based Economy Associations}

\author{
Objective
}

The Social and Solidarity-based Economy as an alternative economic model of endogenous development in Ecuador is mainly characterized by the diversity of sectors grouped in associations, credit unions, communities as well as social and economic units. To ascertain the social and economic impact is a challenge to establish policies aimed to promote these forms of organization; for this, the Superintendence of Social and Solidarity-based Economy -SEPS- in 2013 identified macro dimensions and dimensions that allow to analyze the social balance of the Cooperative sector, advising the need to implement indicators which have to be adaptive to all the recognized associative forms under a suited methodology adapted to the one mentioned before.

In Ecuador during 2016, the associative model represented the $64,61 \%$ of the 9.139 Associations and Credit Unions registered in the SEPS, this indicator delimits the scope of action of this research work which has the purpose of presenting a model for social balance evaluation through the creation, application and validation of dimension indicators to determine the impact of the Associative sector of Social and Solidarity-based Economy.

In fact, the Social Balance must meet various requirements which allow to identify the welfare or the need to generate actions aimed to promote the social sphere, either in business or for this research work, the analysis is addressed to the associative sector of Social and Solidarity-based Economy.

\section{Methodology}

The indicative, deductive and analytic method was applied through the analysis of methodologies proposed by nonprofit organizations structured under a system of indicators that have been applied in practice both locally and internationally, considering the greater relevance of applicability and viability to the reality of the associative sector in Ecuador.

Within the methodological process adopted and adapted for the research, there are six (6) identified stages: 1) Analysis of the experience of the social balance model made by SEPS for the Cooperative and Financial sector and of the international models for nonprofit entities, 2) Determination 
of macro dimensions and dimensions that allows to analyze Social Balance in the associative sector, 3) Identification of impact indicators with qualitative and quantitative characteristics, efficiency, efficacy and effectiveness and their corresponding definition, 4) Validation of the proposed indicators through an experts' analysis, 5) Development of the methodology for social balance evaluation, 6) Validation of the methodological proposal for social balance.

\section{Results}

1. For this research work, the methodologies were considered in the international context with the most similarity to the Ecuadorian reality and to the economic, social and solidarity-based sector. That first exercise allowed to identify some similarities that later were analyzed from different proposals mainly applied in for-profit and non-profit economic sectors.

2. For the determination of the macro dimensions and dimensions that directly influence the social balance in associations of Social and Solidarity-based Economy, it was made a critical analysis of the definition proposed by the SEPS. From the first analysis, it was identified the applicability in seven (7) macro dimensions and seventeen (17) dimensions; additionally, three (3) new dimensions were increased from the international experience (Gender Equity, Accountability, Economic Solidary-based Act) whose concepts were redefined in concordance with the associative reality.

3. The indicators were established according to the definition of the twenty (20) dimensions, having a first exercise with thirty-nine (39) indicators.

4. To validate the indicators, it was carried out an experts' analysis through the Delphi methodology, after the methodological processes and several consensuses, it was established the applicability of thirty (32) indicators. For purposes of indicators reduction, the dimensions were limited to sixteen (16) and six (6) macro dimensions.

5. The social balance evaluation has to promote a critical and descriptive analysis of the initial situation against the final situation (goal) of the association in the financial - social period and the annual management. The structure of data consolidation is done through a chart that allows to systematize the goals achieved in each indicator.

6. The validation of the proposal was made by the application in three (3) associations that provide food and cleaning services in the Zone 2 (Napo and Orellana provinces) due to it is considered the area of greater representativeness and contribution- to the local economy; the results were: Asomureto has an efficient social performance $(77,22 \%)$, although Asopreschac $(73,62 \%)$ and Asojochint $(67,21 \%)$ have a normal social balance. 


\section{Limitations of the research}

The proposal defines an applicability to the associative sector of provision of services within the framework of social and solidarity-based economy; for this purpose, the main economic and associative activities are taken into consideration: construction, tourism and artisanal, agricultural and industrial, textile manufacturing. The proposal considers currently the associative sector, consequently it is necessary for each economic sector to include new management indicators if necessary. As well, it will be interesting to analyze the Community sector and Social Economic Unit through the proposed methodology due to its purposes are not considered "non-profit, human beings over capital".

\section{Conclusions}

The methodology proposed for social balance evaluation in associations of social and solidaritybased economy in Ecuador meets the need of determining the level of endogenous development corresponding to the social and solidarity-based model under the principle of human beings over the capital. The design is friendly and easy to apply in any type of association by the competent authorities.

The research becomes considerably relevant both nationally and internationally, because the policies to foster entrepreneurships in the social and solidarity-based economy sector as a strategy to contribute to fight against poverty, as well as the generation of sources of work allow to differentiate and analyze the real impact of the economic and solidarity-based model.

The results obtained in the validation of the proposal demonstrate the pertinence of the findings, that is the basis to establish new perspectives of associative development that generate the different forms of organization guaranteed by the Social and Solidarity-based Economy Law.

\section{Original Value}

With the application of the proposed methodology, the original value of the investigation is supported by the obtained results which demonstrate the social balance of the associative sector of social and solidarity-based economy. The proposal serves as a model for the application among other similar organizations; currently, the associations have decided to include this methodology due to its easy application because it generates descriptive information which allows to establish improvement actions in those indicators categorized with urgent, immediate and continuity interventions.

KEYWORDS: Social Balance, Social and Solidarity-based Economy, Indicators, Dimension, Association. 


\section{1.- Introducción}

El artículo 283 de la Constitución Política del Ecuador (2008) señala que el sistema económico del Ecuador es social y solidario, reconoce al ser humano como sujeto y fin; integra los sectores económicos públicos, privado, mixto, popular y solidario, siendo regulada de acuerdo a la Ley Orgánica de la Economía Popular y Solidaria y del Sector Financiero Popular y Solidario - LOEPS1.

El artículo 1 de la LOEPS define a la economía popular y solidaria como la "forma de organización económica, donde sus integrantes, individual o colectivamente, organizan y desarrollan procesos de producción, intercambio, comercialización, financiamiento y consumo de bienes y servicio, para satisfacer necesidades y generar ingresos, basadas en relaciones de solidaridad, cooperación y reciprocidad, privilegiando al trabajo y al ser humano como sujeto y fin de su actividad, orientada al buen vivir, en armonía con la naturaleza, por sobre la apropiación, el lucro y la acumulación de capital". En este modelo económico no forman parte las agrupaciones gremiales, profesionales, laborales, culturales, deportivas, religiosas, entre otras que no tengan como actividad económica la producción de bienes o prestación de servicios.

La nueva corriente de orientación de vida conocida como Buen Vivir permite redefinir los conceptos clásicos de una economía tradicionalista, como por ejemplo en el desarrollo, progreso, bienestar e inclusión social. Esta economía comparte un relacionamiento directo con las prácticas de un sistema económico social o lo que llamamos una socio - economía, en el que su contribución beneficia y revaloriza al individuo que desde lo económico dinamiza y potencia la creatividad del trabajo, mientras que desde lo político genera una convergencia de pensamientos que aseguran la dignidad de la vida de todos y desde lo ambiental el reconocimiento de los derechos de la naturaleza.

La política de fomento de los emprendimientos del sector de la economía popular y solidaria como estrategia de contribución a la lucha contra la pobreza, así como la generación de nuevas fuentes de trabajo permiten diferenciar y analizar el real impacto del modelo económico solidario. El modelo asociativo en el país durante el año 2016 representa el 64,61\% de las 9.139 Cooperativas y Asociaciones registradas en la SEPS y contribuye cerca del $60 \%$ del Producto Interno Bruto (Superintendencia de Economía Popular y Solidaria, 2016). Es importante entonces, conocer el impacto

1.- Mediante la LOEPS se crearon tres (3) instituciones públicas encargadas del fomento y promoción, regulación y financiamiento al sector popular y solidario: Instituto Nacional de Economía Popular y Solidaria -IEPS- que tiene como misión el fomento y promoción de esta economía, Superintendencia de la Economía Popular y Solidaria -SEPS- que tiene la misión la supervisión y control de este sector económico y por último la Corporación Nacional de Finanzas Populares y Solidarias -CONAFIPS-, ente encargado de generar mecanismos de inclusión financiera de apoyo al mejoramiento de la calidad de vida de la población de la Economía Popular y Solidaria -EPS- 
de este sector económico en su núcleo asociativo, ya que desde lo social implica todo un conjunto de acciones positivas (Cartes, 2015:1-59).

La Superintendencia de Economía Popular y Solidaria en el año 2013 realizó la investigación denominada "Estudios sobre economía popular y solidaria", en el que se concluye la necesidad de desarrollar indicadores para el análisis y evaluación del impacto en el sector de la economía popular y solidaria en las cuatro (4) formas de organización legalmente constituidas en el país (asociaciones, cooperativas, unidades económicas populares, comunidad).

Para medir el impacto del sector Cooperativo Financiero, la SEPS definió siete (7) macro dimensiones y veinte y cuatro (24) dimensiones que permiten evaluar el Balance Social en esta forma de organización (Superintendencia de la Economía Popular y Solidaria, 2013:177-188), siendo necesario identificar el impacto que se desarrolla en el sistema asociativo, ya que la evaluación sirve de marco de referencia para la formulación de un programa o proyecto, así como las relaciones existentes en los componentes (Acción Social, 2012:11-14).

Este documento tiene como objetivo presentar un modelo de evaluación del balance social mediante la generación, aplicación y validación de indicadores por dimensión que permitan determinar el impacto del sector Asociativo de economía popular y solidaria, siendo éste el de mayor representatividad organizativa del Ecuador. Esta propuesta se convierte en la base para la evaluación y análisis del impacto que generan las formas de organización reconocidas en la Ley Orgánica de Economía Popular y Solidaria.

\section{2.- Marco teórico}

\subsection{Economía Social y Solidaria}

La economía social produce sociedad y no específicamente recursos económicos, ya que genera valores de aprovechamiento del recurso a fin de satisfacer las necesidades de los emprendedores (Coraggio, 2011:45) que mantienen sus actividades económicas en base a la identidad cultural, étnica, social e incluso territorial. Entre los principios de la economía popular y solidaria y sus formas de organización, se encuentran: a) La búsqueda del buen vivir y del bien común, b) La prelación del trabajo 
sobre el capital y de los intereses colectivos sobre los individuales, c) El comercio justo y consumo ético y responsable, d) La equidad de género, e) El respeto a la identidad cultural, f) La autogestión, g) La responsabilidad social y ambiental, la solidaridad y rendición de cuentas, y, h) La distribución equitativa y solidaria de excedentes.

La economía social contempla dos vertientes: 1) De mercado, y 2) No de mercado (Jubeto, Guridi, \& Fernández, 2014:22-23). En la última, ofrecen servicios a terceros que pueden comercializar en los mercados considerando precios de lucro económico no significativos, consiguen sus recursos mayoritariamente gracias a cuotas de socios, aportes externos, etc., y cuyos excedentes (en caso de que los hubiera) no podrían ser apropiados por los miembros de las mismas, cumpliendo así los principios económicos de la economía social y solidaria (Coraggio, 2011:374). En el sector asociativo ecuatoriano, sus miembros realizan acciones en común para desarrollar una actividad económica sin fines de lucro, este proceso se conocen como actos económicos solidarios que permiten el cumplimiento de los objetivos estatutarios.

\subsection{Balance Social}

El balance social se define como el nivel de cumplimiento tanto de los principios como de los objetivos sociales propuestos y que tienen incidencia en su identidad, en el desarrollo social y comunitario, disminución del impacto ambiental, mejora en el nivel educativo y cultural (Asamblea Nacional del Ecuador, 2011), es decir, este proceso muestra las relaciones y actividades desarrolladas que en conjunto buscan mejorar la calidad de vida ${ }^{2}$ de sus miembros o socios.

De igual manera, (Gil, 2010:1-7) indica que el balance social representa un sistema de diagnóstico que abarca una serie de estudios analíticos que determinan la situación social, laboral y económica de la empresa. Se toma en cuenta la diferencia entre Responsabilidad Social Empresarial y el Balance Social; la primera demuestra la gestión de la empresa en la maximización de los resultados económicos teniendo ética en el negocio y dando cumplimiento a la voluntad del empresario frente a actores internos y externos, sociales y/o comunidad (Superintendencia de Economía Popular y Solidaria, 2014:43-48); mientras tanto, el balance social se convierte en un instrumento de gestión que permite planear, organizar, dirigir, controlar y evaluar de manera cuantitativa y cualitativa, ya que al igual del Balance Financiero, éste debe ser evaluado y presentado de acuerdo a un período determinado y frente a metas preestablecidas (Organización Internacional del Trabajo, 2001:12-14).

2.- En Ecuador, el Atlas de las desigualdades socioeconómicas del Ecuador genera el Índice Social Comparativo (ISC) que permite evaluar el avance social del país en los últimos censos poblacionales (1990, 2001, 2010), manteniendo un crecimiento anual del 1,3\% desde 2001 al 2010, llegando a un puntaje total de 68,1\% (Secretaría Nacional de Planificación y Desarrollo, 2013a:22). 
El informe social o balance social, no se debe interpretar por su resultados en expresiones numéricas o porcentuales, por el contrario es necesario identificar y analizar las variaciones o desviaciones que han sufrido las metas establecidas (Organización Internacional del Trabajo, 2001:96), complementariamente, la Comisión de Investigación y Desarrollo -DERES- considera que el Balance Social es un instrumento adicional del balance financiero de la empresa, por tal motivo es necesario identificar los beneficios y acciones sociales que la empresa cumple con los empleados, inversionistas y la comunidad de manera integradora (Desarrollo de la Responsabilidad Social, 2013:13-15).

Entonces, el Balance Social debe cumplir una serie de requisitos que permitan identificar el bienestar o la necesidad de generar acciones que fomenten el ámbito social, ya sea en la empresa ó para el caso del presente estudio, el análisis se direcciona al sector asociativo de economía popular y solidaria, ya que representa el $64,61 \%$ de las distintas formas de organización reconocida y registrada a nivel nacional.

\subsubsection{Metodologías de balance social en el contexto internacional}

A nivel internacional existe una infinidad de propuestas metodológicas para determinar el balance y responsabilidad social, éstas corresponden a las desarrolladas tanto académicas, privadas y de instituciones públicas de una Nación. Las propuestas que permiten llevar a cabo mediciones del impacto social de la actividad económica en los distintos tipos de empresas, son justamente adaptadas a un modelo económico de lucro y no representa algún tipo de significancia al modelo de economía popular y solidaria, por tal motivo, las metodologías citadas a continuación corresponden a aquellos métodos que tienen cierta similitud en su concepto y que reflejan resultados en su aplicación.

En Uruguay, la Asociación de Empresas Privadas desarrolla un "Manual para la preparación e implementación del Balance Social" con el principal objetivo de procurar una concientización de la base social y las relaciones que se desarrollan entre la empresa y los actores sociales, incorporando conceptos que corresponden a la Responsabilidad Social Empresarial. Esta metodología genera un reporte de la contribución social de la empresa, entre los siguientes aspectos: 1) Aporte a la comunidad, 2) Aporte al mejoramiento de la calidad de vida de sus trabajadores, 3) Aporte al cuidado del medio ambiente, 4) Colaboración a causas o proyectos sociales. Para el desarrollo de la metodología, se generan una serie de indicadores de carácter cualitativo y cuantitativo (Desarrollo de la Responsabilidad Social, 2013:21-47).

La propuesta "Balance social como instrumento para la evaluación de la acción social en las entidades no lucrativas", tiene como objetivo el análisis de las características peculiares con carácter eminentemente social, evaluando a través de dimensiones e indicadores de tipo social, sin embargo, se presentan principales dificultades y limitaciones para elaborar el balance social: 1) Dificultad en cuantificar los aspectos sociales en cifras o números, 2) Costos de tiempo y dinero para elaborar el balance social, 3) Poco cultura de realizar este análisis social, 4) Falta de estandarización del término balance social, (Ribas, 2001:115-147). 
El balance social depende de las distintas características que tienen las organizaciones (razón social, grupo asociativo, sector económico, características culturales, entre otras), así como también la definición de indicadores específicos para el sector (Colina \& Senior, 2008:71-77).

En conclusión, existen varios parámetros y propuestas de elaboración del Balance Social, sin embargo, las propuestas (externas) tienen como fin el demostrar las características 0 actividades que las empresas y las entidades no lucrativas realizan desde el ámbito social. Desde el sector de la economía popular y solidaria (en Ecuador) o economía social (a nivel mundial) en cuanto a asociaciones, no se ha generado una metodología que con el desarrollo de indicadores se defina el impacto que tienen las asociaciones.

\subsection{Economía popular y solidaria en el Ecuador}

En el Ecuador, la economía solidaria no se limita a las formas asociativas populares ${ }^{3}$ sino que incluye además las formas públicas (aplicación del principio de redistribución y reciprocidad, seguridad social o los bienes públicos gratuitos) y formas de solidaridad con organizaciones de la sociedad civil. (Coraggio, 2013b:1-7).

El sistema económico es social y solidario, se desenvuelve mediante las distintas formas de organización económica que garantizan el desarrollo de emprendimientos dedicados a la producción de bienes o prestación de servivicios, satisfaciendo principalmente la demanda local y nacional. Muestra de ello son los resultado de los últimos seis (6) años, existiendo un crecimiento del $52 \%$ de organizaciones del sector financiero y no financiero, en el año 2016, existen 3.233 Cooperativas y 5.905 Asociaciones registradas en el sector de la economía popular y solidaria (Superintendencia de Economía Popular y Solidaria, 2016), de éstas últimas, el 48,8\% se concentran en la Serranía ecuatoriana, mientras que en la Amazonía representan el 15,80\%. (Superintendencia de Economía Popular y Solidaria, 2012:1-15)

Una característica estructural de la economía no tradicional ecuatoriana ha sido el peso económico de este sector que estadísticamente representa el 60\% del PIB (Instituto Nacional de Economía Popular y Solidaria, 2013:25-26), mediante la producción de bienes y prestación de servicios que promueven el desarrollo nacional, estas actividades que se realizan de manera asociativa corrobora el término "solidario" como una consideración objetiva del dinamismo económico ecuatoriano (Coraggio, 2013a:4).

3.- La Ley de Economía Popular y Solidaria y del Sector Financiero Popular sustenta cuatro (4) tipos de organizaciones en el Ecuador: Asociaciones, Comunidades, Cooperativas (relacionado con producción, consumo, ahorro y crédito, servicios, vivienda) y Unidades Económicas Popular (emprendimiento productivos individuales o personales). 
En el año 2016, a través de los programas impulsados por el Gobierno Nacional en los que participan las asociaciones de economía popular y solidaria, se han vinculado 458 asociaciones y 3.877 unidades económicas populares que en la contratación pública (mercado público) representa un monto de $\$ 83^{\prime} 520.402,63$, mientras que la comercialización de los bienes y servicios en este mismo sector económico en el mercado privado es de \$12’006.119,19 (Instituto Nacional de Economía Popular y Solidaria, 2016).

En la Zona de Planificación 2 del país, integrado por las provincias de Napo y Orellana, la vinculación al mercado público y privado de los sectores económicos asociativos ${ }^{4}$ representa el 6,24\% a nivel nacional, es decir, un total de $\$ 5^{\prime} 959.653,99$, distribuidos de la siguiente manera: Sector alimentación (50,63\% / \$ 3’017.533,25), Sector textil (30,23\% / \$1'801.713,71), Sector metalmecánica, construcción y limpieza $(15,34 \%$ / \$ 914.072,62), Sector agroindustrial $(3,46 \%$ / \$206.150,25), Sector artesanal, turismo y bioemprendimientos (0,34\% / \$ 20.184,16) (Instituto Nacional de Economía Popular y Solidaria, 2016).

Este tipo de economía enmarcado en el paradigma desarrollista genera oportunidades de fuentes de trabajo, en el cual participan todos los sectores económicos (pequeño comercio, el artesanal y el campesino), manteniendo emprendimientos a nivel asociativos y/o individuales, multiplicando las formas de trabajo digno y remunerado por lo que es necesario conjugar la base ética del paradigma del desarrollo, a través de fundamentos que promuevan el bien de sus asociados (Astroulakis, 2013: 33-53).

\subsubsection{Balance social en el Ecuador}

La Superintendencia de la Economía Popular y Solidaria -SEPS- define siete (7) macro dimensiones y veinte y cuatro (24) dimensiones a ser consideradas en el análisis de Balance Social Cooperativo (Tabla No. 1), entre sus conclusiones destaca la necesidad de definir una serie de indicadores que aporten a cada dimensión, instrumento que en el periodo de desarrollo de esta investigación no se define oficialmente; se aclara que la metodología propuesta por la SEPS es de aplicación al sector Cooperativo Financiero, sin embargo, recomienda mejorar y adaptar la metodología propuesta de acuerdo a la realidad del sector asociativo no financiero.

4.- A nivel local, los sectores productivos se han agrupado en 5 sectores: 1) Agroindustria y agropecuario 37,25\%, 2) Metalmecánico, mantenimiento, limpieza 25,49\%, 4) Turismo, artesanal y bioemprendimientos 17,65\%, 4) Alimentación 10,78\%, 5) Manufactura textil 8,82\%. Fuente: Instituto Nacional de Economía Popular y Solidaria - Dirección Técnica Zonal 2, 2016. 


\section{Tabla 1. Macro dimensiones y dimensiones establecidas por la SEPS}

\begin{tabular}{|l|l|}
\hline Macro dimensión SEPS & Dimensiones \\
\hline 1. Prelación del trabajo sobre el capital & 1.1. Prelación del trabajo sobre el capital \\
los individuales & 1.2. Prelación de los intereses colectivos sobre los individuales \\
\hline 2. Asociación voluntaria, equitativa y & 1.3. Ocio liberador \\
respeto a la identidad cultural & 2.1. Accesibilidad asociativa y cooperativa \\
& 2.2. Retiro de asociados \\
2.3. Conocimiento cooperativo y del sistema económico social y solidario \\
por parte de los miembros
\end{tabular}

FUENTE: SEPS, 2013. 


\section{3.- Metodología}

Se utilizó el método inductivo, deductivo y analítico, mediante un análisis de las metodologías propuestas de organizaciones sin fines de lucro estructuradas bajo un sistema de indicadores y que han sido aplicadas en la práctica tanto a nivel nacional como internacional, considerando la mayor relevancia de aplicabilidad y viabilidad a la realidad del sector asociativo en el Ecuador.

Dentro del proceso metodológico adoptado y adaptado en la investigación se identifican seis (6) etapas: 1) Análisis de la experiencia del modelo de balance social realizado por la SEPS para el sector Cooperativista Financiero y de los modelos internacionales para entidades no lucrativas, 2) Determinación de las macro dimensiones y dimensiones que permite analizar el Balance Social el sector asociativo, 3) Identificación de indicadores de impacto con características cualitativas, cuantitativas, eficiencia, eficacia y efectividad, y su correspondiente definición, 4) Validación de los indicadores propuestos mediante un análisis de expertos, 5) Construcción de la metodología de evaluación del balance social, 6) Validación de la propuesta metodológica de balance social.

La propuesta fue validada mediante la aplicación en asociaciones de prestación de servicios de alimentación y limpieza de la Zona 2 (provincias de Napo y Orellana) del Ecuador, siendo éste segmento el de mayor representatividad y aporte a la economía local, no por su cantidad de asociaciones y socios, sino por la consolidación de procesos de prestación de servicios en empresas e instituciones públicas y privadas de la región amazónica, mediante la vinculación a proyectos emblemáticos del país que económicamente representa una vinculación al mercado público y privado de $\$ 3{ }^{\prime} 017.533,25$ (50,63\% de la contratación territorial Zonal), entre estos: Hidroeléctrica Coca Codo Sinclair, Unidades Educativas del Milenio, Hospitales de primer nivel y Centros Infantiles del Buen Vivir.

\subsection{Análisis de la experiencia del modelo de balance social}

Para el análisis del modelo del balance social, se llevó a cabo la interpretación de la metodología aplicada por la SEPS para evaluar el Balance Social en el Sistema Cooperativista Financiero del Ecuador y la experiencia internacional para el análisis del Balance Social en organizaciones lucrativas y no lucrativas (Tabla No. 2), si bien el contexto internacional muestra una infinidad de metodologías probadas y no, para la presente investigación se escogieron aquellas puestas en marcha que sin ser únicas tienen mayor relación al caso ecuatoriano, esta actividad permitió identificar las características principales del Balance Social como también las sugerencias para el proceso metodológico y los factores que deben priorizarse para la realidad asociativa del país. 


\section{Tabla 2. Análisis de la experiencia del modelo de balance social con indicadores por dimensión}

\begin{tabular}{|l|l|}
\hline Institución & Documento \\
\hline $\begin{array}{l}\text { Superintendencia de Economía Popular } \\
\text { y Solidaria: Balance Social Cooperativista }\end{array}$ & $\begin{array}{l}\text { 1. Estudios sobre economía popular y solidaria. } \\
\text { 2. Serie de estudios sobre economía popular y solidaria - Contextos de la } \\
\text { "Otra Economía". } \\
\text { 3. Balance Social: Modelo y primeros resultados agregados. }\end{array}$ \\
\hline $\begin{array}{l}\text { Organización Internacional de Trabajo: } \\
\text { Asociación Nacional de Industriales de Colombia }\end{array}$ & Manual de Balance Social. \\
\hline $\begin{array}{l}\text { Desarrollo de la Responsabilidad Social - } \\
\text { DERES }\end{array}$ & $\begin{array}{l}\text { Manual para la preparación e implementación del Balance Social en el } \\
\text { Uruguay, aplicado a empresas. }\end{array}$ \\
\hline Ribas, M. 2001 & $\begin{array}{l}\text { Balance social como instrumento para la evaluación de la acción social } \\
\text { en las entidades no lucrativas }\end{array}$ \\
\hline
\end{tabular}

FUENTE: Elaboración propia.

\subsection{Determinación de las macro dimensiones y dimensiones}

Al igual que la metodología adoptada por la SEPS para el desarrollo del Balance Social, el diseño metodológico fue el siguiente:

- Analizar la realidad del sistema asociativo de la economía popular y solidaria.

- Decidir sobre la adopción de un modelo o metodología existente en la actualidad, o por el contrario acordar la creación de un modelo propio de balance social.

- Asociar la coexistencia o no, de diversos modelos aceptados como válidos para la implementación del Balance Social en cumplimiento de la normativa.

- Utilizar el mayor número posible de aspectos metodológicos. (Superintendencia de la Economía Popular y Solidaria, 2013:166-167)

Se tomaron como referencia las macro dimensiones y dimensiones señaladas en la Tabla No. 1, sin embargo, de acuerdo a la definición y alcance de cada dimensión se procedió a identificar las características aplicables al sector asociativo mediante la valoración de criterio (aplica y no aplica) a las siete (7) macro dimensión y posteriormente a cada dimensión. Adicionalmente, por la particularidad del modelo asociativo fue necesario establecer nuevas dimensiones y/o reconsideración de la definición de las dimensiones inicialmente propuestas por la SEPS.

\subsection{Identificación de indicadores}

Para establecer los indicadores sociales se tomaron en cuenta los aspectos claves contenidos en la definición de cada dimensión, identificando si éstos son de tipo porcentual, numérica y/o nominal (Cecchini, 2005:13-17). Los indicadores propuestos cumplieron con las características en cuanto a su 
clasificación: cuantitativos y cualitativos (medición), impacto (nivel de intervención), eficacia, eficiencia y efectividad (calidad). (Hernández, 2001:93-97). Cada uno de los indicadores mantuvieron una estructura de: definición, fórmula de cálcula y tipo de indicador.

\subsection{Validación de indicadores}

Para validar la propuesta de indicadores por dimensión, fue necesario tomar las consideraciones y valoraciones de siete (7) profesionales involucrados en el sector de la economía popular y solidaria desde el ámbito público, privado y la academia; por lo que con el análisis de expertos (metodología Delphi) (Astigarraga, 2004:2-14), previo a una interacción entre los participantes frente a los indicadores propuestos y pre analizados, se transmitió un instrumento con el que se valoraron los indicadores mediante una escala de importancia en rango de 1 a 5 (1: nada importante, 2: poco importante, 3: medianamente importante, 4: importante y 5 : muy importante) posterior a las evaluaciones, el proceso culminó con la socialización y conjetura de los indicadores que influyen directamente en el balance social ante los expertos participantes.

\section{Tabla 3. Matriz de evaluación a indicadores por dimensión}

\begin{tabular}{|c|c|c|c|c|c|c|c|c|c|c|}
\hline \multirow[b]{2}{*}{$\begin{array}{c}\text { Macro } \\
\text { dimensión }\end{array}$} & \multirow[b]{2}{*}{ Dimensión } & \multirow[b]{2}{*}{ Indicador } & \multirow[b]{2}{*}{ Definición } & \multirow[b]{2}{*}{ Cálculo } & \multirow[b]{2}{*}{ Unidad } & \multicolumn{5}{|c|}{ Escala de valoración } \\
\hline & & & & & & $\begin{array}{c}\text { (1) } \\
\text { Nada } \\
\text { importante }\end{array}$ & $\begin{array}{c}\text { (2) } \\
\text { Poco } \\
\text { importante }\end{array}$ & \begin{tabular}{|c|}
$(3)$ \\
Medianamente \\
importante
\end{tabular} & $\begin{array}{c}4) \\
\text { Importante }\end{array}$ & $\begin{array}{c}\text { (5) } \\
\text { Muy } \\
\text { importante }\end{array}$ \\
\hline $\begin{array}{l}7 \text { macro } \\
\text { dimensio- } \\
\text { nes inicial- } \\
\text { mente } \\
\text { planteadas }\end{array}$ & $\begin{array}{l}20 \text { dimen- } \\
\text { siones ini- } \\
\text { cialmente } \\
\text { planteadas }\end{array}$ & $\begin{array}{c}39 \text { indicado- } \\
\text { res inicial- } \\
\text { mente } \\
\text { planteadas }\end{array}$ & $\begin{array}{l}\text { Cada indi- } \\
\text { cador con- } \\
\text { tenía la } \\
\text { explicación } \\
\text { que corres- } \\
\text { pondía en } \\
\text { cuando a su } \\
\text { medición. }\end{array}$ & $\begin{array}{c}\text { Cada indi- } \\
\text { cador tiene } \\
\text { una fórmula } \\
\text { de cálculo }\end{array}$ & $\begin{array}{l}\text { 1) Nominal } \\
\text { 2) Porcentual } \\
\text { 3) Numérica }\end{array}$ & \multicolumn{5}{|c|}{$\begin{array}{l}\text { Para la evaluación del Balance Social se tomarán en considera- } \\
\text { ción los indicadores que tengan una escala de valoración prome- } \\
\text { dio entre } 4 \text { y } 5 \text { de la calificación de los expertos. Los indicadores } \\
\text { que tengan una valoración entre } 1 \text { y } 3 \text {, serán nombrados como } \\
\text { aquellos que no generan impacto en el Balance Social. }\end{array}$} \\
\hline
\end{tabular}

FUENTE: Elaboración propia.

3.5. Construcción de la metodología de Balance Social para el sector asociativo de economía popular y solidaria

Del resultado de los indicadores priorizados se elaboró un sistema de preguntas por cada indicador, permitiendo la construcción de encuestas. Para consolidar los datos obtenidos se estructuró una matriz que contiene: macro dimensiones, dimensiones, indicador, definición, metal referencial, resultados obtenidos en la asociación, diferencia en porcentaje de cumplimiento frente a la meta y el 
cumplimiento comparado al $100 \%$ sobre la meta, en este último caso se estandariza a un mismo peso cada indicador.

En la evaluación por indicadores de gestión, se establecieron las respectivas metas a cada indicador, conforme a la Ley y Reglamento de la Economía Popular y Solidaria, los contenidos de los Estatutos de conformación de las asociaciones, así como las metas mínimas propias del sector en cuanto a generar trabajo, es decir, la razón por la cual se crean las asociaciones (ámbito económico productivo, social y ambiental), lo que genera finalmente la propuesta de la presente investigación.

\subsection{Validación de la propuesta metodológica para determinar del impacto del Balance Social}

Para validar la metodología, se aplicaron los indicadores en asociaciones de eps en la Zona de Planificación 2 del país conformada por las provincias de Napo y Orellana, conforme la base generada por el Instituto Nacional de Economía Popular y Solidaria (Tabla No. 4), recogiendo información a través de herramientas como la encuesta que se aplicó al administrador/a, socios y trabajadores (no socios), obteniendo resultados porcentuales del impacto del balance social en las asociaciones.

La interpretación de los resultados, ya sea por cada macro dimensión y/o por cada indicador se realiza mediante la definición de rangos de interpretación bajo una escala porcentual de: 0,01\% $25,00 \%, 25,01 \%-50,00 \%, 50,01-75,00 \%, 75,01-100 \%$.

\subsection{Población y muestra de estudio}

En cuanto a la población de estudio y unidad de análisis, correspondió a tres (3) asociaciones ${ }^{5}$ de alimentación y limpieza legalmente constituidas en la Zona 2, de las cuales, se desprende un total de sesenta y nueve (69) asociados y diez (10) trabajadores.

5.- Estas asociaciones tienen como objeto social la comercialización de servicios de alimentación y limpieza para entidades públicas y privadas que coadyuven al desarrollo social, económico y cultural. Este acápite es el reconocido por la Superintendencia de Economía Popular y Solidaria, tomando como base el artículo 147 literal c de la Ley y artículo 2 del Reglamento General. 


\section{Tabla 4. Población y muestra}

\begin{tabular}{|c|l|c|c|}
\hline No. & Asociaciones & $\begin{array}{c}\text { Número de } \\
\text { socios/as }\end{array}$ & $\begin{array}{c}\text { Número de trabajadores } \\
\text { no socios }\end{array}$ \\
\hline $\mathbf{1}$ & $\begin{array}{l}\text { Asociación de prestación de bienes, servicios de alimentación } \\
\text { y limpieza el Sumak Kawsay de San José de Chonta Punta } \\
\text { "ASOJOCHONT" }\end{array}$ & 25 & 6 \\
\hline $\mathbf{2}$ & $\begin{array}{l}\text { Asociación de prestación de servicios de limpieza y alimentación } \\
\text { Nuevo Milenio Santa Rosa de El Chaco "ASOPRESCHAC" }\end{array}$ & 30 & 1 \\
\hline $\mathbf{3}$ & $\begin{array}{l}\text { Asociación de servicios de alimentación y limpieza Mujeres de } \\
\text { Loreto "ASOMURETO" }\end{array}$ & 69 & 14 \\
\hline \multicolumn{2}{|l}{ Total muestra } & & 10 \\
\hline
\end{tabular}

FUENTE: IEPS - DTZ2, 2016.

\section{4.- Resultados de la investigación}

\subsection{Análisis de experiencias en Balance Social}

El Balance social es considerado como una herramienta que brinda información sobre aspectos subjetivos, objetivos y cuantitativos de la institución que se analice; en el contexto internacional existen varias propuesta para elaborar el balance social enfocado principalmente al sector Empresarial lucrativo y aquellas Entidades no lucrativas.

Para la presente propuesta se consideran las metodologías no únicas pero más cercanas a la realidad ecuatoriana y del sector económico popular y solidario, no encontrando una metodología precisa para el sector asociativo, pero se consideran ciertas semejanzas que fueron necesarios analizar de las siguientes propuestas:

1) Asociación Nacional de Industriales de Colombia, en la metodología propuesta a través de la Organización Internacional de Trabajo, propone la evaluación del balance social a través de ochenta y tres (83) indicadores del área interna y cincuenta y dos (52) indicadores del área externa, siempre que exista una serie de condiciones que aseguren un proceso continuo de gestión empresarial. 
2) La Agencia de Desarrollo de la Responsabilidad Social, en el Manual para la preparación e implementación del Balance Social en el Uruguay, enfatiza principalmente a los conceptos de Responsabilidad Social Empresarial. La metodología propuesta plantea cuatro (4) componentes de evaluación, de éstos se propone una diferenciación a las empresas de carácter familiar, unipersonal y multinacional. La estratificación es la siguiente: i) Empresas con menos de 20 empleados: se incluye las de tipo unipersonal, familiar, pequeñas sociedad de hecho y derecho dedicadas a la comercialización de productos o servicios que cuentan con una limitada información por el tipo y giro del negocio, así como los hábitos de manejo administrativo en muchas ocasiones no generan información económico financiera y de desempeño. ii) Empresas entre 20 a 100 empleados: llamadas mediana empresa, éstas al contar con información económica, financiera y de manejo de personal, permitiría su aplicabilidad en la elaboración del balance social como complemento a la información financiera que generan. iii) Empresas con más de 100 empleados: refiriendo a las empresas que son subsidiadas por organismos multinacionales, sociedades anónimas, empresas de intermediación financiera, empresas mixtas y empresas públicas. Esta clasificación es la más acertada para la implementación del manual del balance social, ya que dispondría de toda la información que alimentaría a los indicadores propuestos; el principal problema para este sector radica en la transparencia de la información.

3) Ribas, M. 2001para el análisis del balance social plantea cuarenta (40) indicadores de tipo general que caracterizan a diferentes dimensiones de orden social para grupos no lucrativos, es decir, los aspectos que se desarrollan en el campo de la economía social, sin embargo, también concluye que tanto las Fundaciones como Asociaciones deben ser tratados de un modo especial en todos los ámbitos en el balance social. Si bien, estas metodologías concuerdan en que cada sector económico y región tienen particularidades que se deben analizar y plantear en un contexto más específico, señalando la necesidad de estandarizar un modelo que se adapte a cada organización permitiendo conocer el balance social.

En el contexto Nacional, la Superintendencia de la Economía Popular y Solidaria es el órgano de control de este sector económico, el mismo que entre sus requisitos exige la presentación de Balances Económico y Social de las formas de organización establecida en el artículo 22 del Reglamento a la Ley de la Economía Popular y Solidaria. Para el efecto, en el año 2013 la SEPS define siete (7) macro dimensiones y veinte y cuatro (24) dimensiones a ser consideradas en el análisis de Balance Social Cooperativo Financiero, entre sus conclusiones destaca la necesidad de definir una serie de indicadores que aporten a cada dimensión, instrumento que en el periodo de desarrollo de esta investigación no se define oficialmente; se aclara que la metodología propuesta por la SEPS es de aplicación al sector Cooperativo Financiero, recomendando que para el sector asociativo se deberá mejorar y adaptar la propuesta de análisis de balance social de acuerdo a la realidad asociativa. 
4.2. Determinación de Macro dimensiones y Dimensiones que intervienen en la evaluación del balance social

El análisis de las experiencias de balance social (Tabla No. 2) permitió encontrar ciertas similitudes aplicables al modelo asociativo en el Ecuador. Para determinar el marco de dimensiones que influyen directamente al balance social en asociaciones de EPS se realizó un análisis crítico de la definición propuesta por la SEPS, de este primer análisis se concluyó que existe similitudes de aplicabilidad en las siete (7) macro dimensiones, en cuanto a las dimensiones se identificaron la influencia directa de diecisiete (17) siendo necesario reformular su nombre, adicionalmente se incrementaron tres (3) nuevas dimensiones (Equidad de Género, Rendición de cuentas, Acto económico solidario) que tienen concordancia y aplicabilidad al modelo asociativo, considerando además la alternativa de redefinir cada concepto de acuerdo a la realidad asociativa.

\section{Tabla 5. Macro dimensiones y dimensiones identificadas para analizar el balance social en asociaciones de EPS}

\begin{tabular}{|c|c|}
\hline Macro dimensión SEPS & Dimensiones \\
\hline $\begin{array}{l}\text { 1. Prelación del trabajo sobre el capital } \\
\text { y de los intereses colectivos sobre } \\
\text { los individuales }\end{array}$ & $\begin{array}{l}\text { 1. Prelación del trabajo sobre el capital } \\
\text { 2. Prelación de los intereses colectivos sobre los individuales } \\
\text { 3. Ocio liberador }\end{array}$ \\
\hline $\begin{array}{l}\text { 2. Asociación voluntaria, equitativa y } \\
\text { respeto a la identidad cultural }\end{array}$ & $\begin{array}{l}\text { 4. Accesibilidad asociativa } \\
\text { 5. Equidad de género } \\
\text { 6. Conocimiento del sistema económico social y solidario por parte de los miembros } \\
\text { 7. Pérdida de la calidad de asociado }\end{array}$ \\
\hline 3. Autogestión y autonomía & $\begin{array}{l}\text { 8. Acceso a cargos administrativos y de gestión } \\
\text { 9. Control democrático por los socios } \\
\text { 10. Acuerdos con otras organizaciones } \\
\text { 11. Relación con el Estado }\end{array}$ \\
\hline $\begin{array}{l}\text { 4. Participación económica, solidaria y } \\
\text { distribución equitativa de utilidades } \\
\text { o excedente. }\end{array}$ & $\begin{array}{l}\text { 12. Utilización de utilidades } \\
\text { 13. Rendición de cuentas }\end{array}$ \\
\hline 5. Educación, capacitación y comunicación & $\begin{array}{l}\text { 14. Desarrollo de las capacidades de los actores relacionado a la asociación } \\
\text { 15. Promoción de la economía popular y solidaria. }\end{array}$ \\
\hline $\begin{array}{l}\text { 6. Cooperación e integración del Sector } \\
\text { Económico Popular y Solidario }\end{array}$ & $\begin{array}{l}\text { 16. Intercooperación (Solidaridad con entidades del sector de la economía } \\
\text { popular y solidaria) }\end{array}$ \\
\hline $\begin{array}{l}\text { 7. Comercio justo, comunidad, medio } \\
\text { ambiente y Acto económico solidario }\end{array}$ & $\begin{array}{l}\text { 17. Comercio justo } \\
\text { 18. Comunidad } \\
\text { 19. Medio ambiente } \\
\text { 20. Acto económico solidario }\end{array}$ \\
\hline
\end{tabular}

FUENTE: Elaboración propia. 
Este proceso tuvo como un primer resultado las definiciones de las macro dimensiones (Anexo No. 1) y dimensiones (Anexo No. 2) que son aplicables y tienen relación directa al modelo asociativo ecuatoriano. La base teórica de las macro dimensiones corresponde al análisis y empate de definiciones establecida por la SEPS y lo determinado en la LOEPS y su Reglamento General

\subsection{Identificación de indicadores}

Las definiciones de las dimensiones marcan la pauta para identificar los elementos claves que intervienen o se conforman entre sí, por tal motivo, previo consenso entre distintos profesionales se establecieron y definieron treinta y nueve (39) indicadores (Anexo No. 3), de los cuales, siete (7) fueron de carácter nominal, cinco (5) indicadores numéricos y veinte y siete (27) de carácter porcentual.

\subsection{Validación de indicadores}

Del análisis de expertos se tuvo como resultado final la consideración de seis (6) macro dimensiones, dieciséis (16) dimensiones (Tabla No. 6) y treinta y dos (32) indicadores, de este último, cuatro (4) son de carácter nominal, veinte y tres (23) son de carácter porcentual y cinco (5) son indicadores de carácter numérico (Tabla Anexo No. 3). Es necesario puntualizar que al tener el mismo criterio de valoración entre los expertos, los resultados mostraron las concordancias en la puntuación asignada, siendo socializada entre los evaluadores con quienes se concluyó que los indicadores obtuvieron una aprobación unánime, razón por la cual dichos indicadores conforman la propuesta en el presente documento. 


\section{Tabla 6. Macro dimensiones y dimensiones que aportan al Balance Social}

\begin{tabular}{|l|l|}
\hline Macro dimensión & Dimensiones \\
\hline $\begin{array}{l}\text { 1. Prelación del trabajo sobre el capital y de los } \\
\text { intereses colectivos sobre los individuales }\end{array}$ & 1. Prelación del trabajo sobre el capital \\
\hline 2. Asociación voluntaria, equitativa y respeto a la & 2. Prelación de los intereses colectivos sobre los individuales \\
identidad cultural & 4. Equidad de género \\
& 5. Conocimiento del sistema económico social y solidario por \\
& parte de los miembros \\
\hline 3. Autogestión y autonomía & 6. Acceso a cargos administrativos y de gestión \\
& 7. Control democrático por los socios \\
\hline 4. Participación económica, solidaria y distribución & 8. Acuerdos con otras organizaciones \\
equitativa de utilidades o excedente. & 9. Relación con el Estado \\
\hline 5. Educación, capacitación y comunicación & 10. Utilización de utilidades \\
& 11. Rendición de cuentas \\
\hline 6. Comercio justo, comunidad, medio ambiente & 12. Desarrollo de las capacidades de los actores relacionado a la \\
y Acto económico solidario & 13. Comercio justo \\
& 14. Comunidad \\
& 15. Medio ambiente \\
& 16. Acto económico solidario \\
\hline
\end{tabular}

FUENTE: Elaboración propia.

\subsection{Metodología de evaluación del balance social}

Considerando que la evaluación del balance social debe propiciar un análisis crítico y descriptivo de la situación inicial (meta) frente a la situación final de la asociación en el ejercicio económico - social y de gestión anual, se establece un cuadro que permite sistematizar los logros alcanzados en cada indicador (Tabla No. 7).

\section{Tabla 7. Consolidación de resultados obtenidos por cada indicador}

\begin{tabular}{|c|c|c|c|c|c|c|c|c|}
\hline $\begin{array}{c}\text { Macro } \\
\text { dimensión } \\
\text { SEPS }\end{array}$ & $\begin{array}{c}(2) \\
\text { Dimensiones }\end{array}$ & $\begin{array}{c}(3) \\
\text { Indicador }\end{array}$ & $\begin{array}{c}(4) \\
\text { Definición }\end{array}$ & $\begin{array}{c}(5) \\
\text { Meta referen- } \\
\text { cial numéricay y } \\
\text { porcentual }\end{array}$ & $\begin{array}{c}(6) \\
\text { Meta } \\
\text { establecida }\end{array}$ & $\begin{array}{c}(7) \\
\text { Resultado } \\
\text { obtenido en la } \\
\text { asociación }\end{array}$ & $\begin{array}{c}(8) \\
\text { Diferencia en } \\
\% \text { de cumpli- } \\
\text { miento frente } \\
\text { a la meta }\end{array}$ & $\begin{array}{c}\text { Cumplimiento } \\
\text { comparado al } \\
100 \%\end{array}$ \\
\hline & & & & & & & & \\
\hline
\end{tabular}

FUENTE: Elaboración propia 
1. Macro dimensión SEPS: Corresponde a las establecidas para el análisis del Balance Social. Es necesario identificar que cada macro dimensión contiene la respectiva dimensión e indicadores.

2. Dimensión: Corresponde a cada dimensión establecida.

3. Indicador: Corresponde a cada indicador establecida por cada dimensión.

4. Definición: Corresponde a la definición de cada indicador.

5. Meta referencial numérica y porcentual: Esta columna identifica la meta que se establece en la evaluación, existen metas que son de carácter porcentual y otras de carácter numérico.

6. Meta establecida: La meta se establece al inicio del ejercicio fiscal. Estas metas están establecidas por la Junta General en referencia lo requerido por el Administrador/a de la asociación. En asociaciones nuevas y que no han tenido planificación previa, se analizará la realidad actual o metas máximas establecidas en esta metodología, la LOEPS o el reglamento interno de la asociación.

7. Resultado obtenido en la asociación: Corresponde al resultado final alcanzado e identificado en la encuesta aplicada, de acuerdo a la fórmula de cálculo definida para cada indicador.

8. Diferencia en $\%$ de cumplimiento frente a la meta: Es la diferencia porcentual entre el valor obtenido y la meta. Esta diferencia en porcentaje puede ser negativa si la meta no se alcanzó o positiva si fue superada. Tomar en cuenta que existen valores numéricos que se deberán transformar a porcentajes.

La fórmula de cálculo es: $1-\frac{\text { Resultado obtenido }}{\text { Meta }}$; se considera que la unidad (1) corresponde
al $100 \%$.

9. Cumplimiento comparado al 100\%: El cumplimiento de cada indicador debe ser relacionado con la puntuación máxima al $100 \%$ en cada indicador.

La fórmula de cálculo en formato condicional es:

Resultado obtenido $=0 \%$; $\rightarrow$ el valor obtenido es $0 \%$, caso contrario el resultado es la diferencia en $\%$ de cumplimiento frente a la meta del $100 \%$.

Finalmente, para la interpretación del Balance Social se sistematizará en un cuadro resumen que identifica el porcentaje promedio de cumplimiento obtenido en cada macro dimensión, representado de la siguiente manera: 


\section{Tabla 8. Balance Social_Resumen por macro dimensión}

\begin{tabular}{|c|c|c|c|c|}
\hline $\begin{array}{c}(\mathbf{1}) \\
\text { MACRO DIMENSIÓN }\end{array}$ & $\begin{array}{c}(2) \\
\text { Meta }\end{array}$ & $\begin{array}{c}(3) \\
\text { Resultado obtenido }\end{array}$ & $\begin{array}{c}(4) \\
\text { Diferencia en \% de } \\
\text { cumplimiento frente a la meta }\end{array}$ & $\begin{array}{c}\text { (5) } \\
\text { Balance } \\
\text { Social }\end{array}$ \\
\hline \multicolumn{3}{|c|}{ Balance Social (+) ó (-) } & (Valor en \%) \\
\hline
\end{tabular}

FUENTE: Elaboración propia.

Los casilleros 2, 3, 4 y 5 corresponden al valor porcentual promedio obtenido de todos los indicadores que conforman cada dimensión y correspondientemente a cada macro dimensión. De requerir, el investigador podrá obtener y analizar los resultados por cada dimensión, bajo los mismos criterios indicados.

La consideración que debe cumplir porcentualmente deberá ser positiva, es decir, si es mayor 0 igual a +0.01 se concluirá que la asociación cumple varios factores, siendo necesario realizar un análisis por cada macro dimensión e indicador para identificar aquellos que se debe fortalecer e implementar nuevas políticas que coadyuven a generar un mayor compromiso social asociativo. Los rangos de interpretación que se aplicarán a cada indicador son los siguientes: 0,01\% - 25,00\% (Desempeño deficiente: se requiere intervención urgente, por lo que la asociación debe plantear nuevas actividades con sus respectivas metas, promoviendo la participación de todos los involucrados. En su planificación anual será necesario priorizar presupuesto con las actividades asociativas requeridas), 25,01\% - 50,00\% (Desempeño bajo lo normal: intervención medianamente requerida. La asociación debe enfatizar éstas actividades y cumplir periódicamente aquellas que se consideran alcanzables), 50,01$75,00 \%$ (Desempeño normal: la asociación delimitará ciertas actividades de mejora que permita alcanzar el total de su cumplimiento), 75,01 - 100\% (Desempeño social eficiente: la asociación deberá mantener la continuidad con las actividades que han desarrollado).

\subsection{Validación de la propuesta metodológica}

En la Zona de planificación 2 del Ecuador se desarrollan proyectos emblemáticos, estratégicos y programas de políticas públicas que permiten el acceso de una vida plena de la población, esto ha permitido fomentar y vincular distintas actividades económicas productivas y de servicios locales que impulsan el sector de economía popular y solidaria principalmente la prestación de servicios de alimentación.

La metodología de indicadores por dimensión para la evaluación del balance social de asociaciones de EPS se realizó mediante la aplicación de encuestas tanto al administrador, socios y trabajadores de las asociaciones de prestación de servicios de alimentación y limpieza de las provincias de Napo y Orellana. 
A continuación se extrae un análisis comparativo que permite poner en perspectiva los resultados obtenidos en cada macro dimensión de las tres (3) asociaciones consideradas en la investigación:

\section{Tabla 9. Análisis comparativo del Balance Social de las 3 asociaciones}

\begin{tabular}{|l|cccc|}
\hline MACRO DIMENSIÓN & Meta & ASOJOCHONT & ASOPRESCHAC & ASOMURETO \\
\hline $\begin{array}{l}\text { Prelación del trabajo sobre el capital y de los } \\
\text { intereses colectivos sobre los individuales }\end{array}$ & $83,33 \%$ & $73,33 \%$ & $111,11 \%$ & $114,29 \%$ \\
$\begin{array}{l}\text { Asociación voluntaria, equitativa y respeto } \\
\text { a la identidad cultural }\end{array}$ & $67,50 \%$ & $68,67 \%$ & $69,44 \%$ & $54,76 \%$ \\
$\begin{array}{l}\text { Autogestión y autonomía } \\
\text { Participación económica, solidaria y distribución }\end{array}$ & $76,00 \%$ & $65,19 \%$ & $65,05 \%$ & $84,76 \%$ \\
$\begin{array}{l}\text { equitativa de utilidades o excedente. } \\
\text { Educación, capacitación y comunicación }\end{array}$ & $76,00 \%$ & $86,00 \%$ & $91,28 \%$ & $90,48 \%$ \\
$\begin{array}{l}\text { Comercio justo, comunidad, medio ambiente } \\
\text { y Acto económico solidario }\end{array}$ & $85,71 \%$ & $61,27 \%$ & $58,18 \%$ & $48,16 \%$ \\
\hline Balance Social & $83,75 \%$ & $48,81 \%$ & $46,68 \%$ & $70,89 \%$ \\
\hline
\end{tabular}

FUENTE: Elaboración propia. Datos resumen de la aplicación de los indicadores alcanzados por cada asociación.

De los resultados obtenidos, Asomureto es quien obtiene un desempeño social eficiente $(77,22 \%)$, mientras que Asopreschac (73,62\%) y Asojochont $(67,21 \%)$ mantienen un desempeño del balance social considerado como normal. Sin embargo, el análisis de los indicadores se debe particularizar, ya que, son aquellos que la asociación en el siguiente periodo de actividades (ejercicio fiscal) debe tomar énfasis en su mejoría y/o replanteamiento de actividades no cumplidas, sin descuidar el cumplimiento de los indicadores que obtuvieron resultados óptimos.

En los tres casos, es necesario fomentar las actividades que tienen relación al acto económico solidario, ya que como muestran los resultados de las encuestas aplicadas, la rentabilidad económica de los negocios al menos en el año 2015 no fue representativa económicamente debido a la reinversión superior al $75 \%$ de las utilidades generadas, reduciendo el aporte económico a los socios y trabajadores. 


\section{5.- Discusión}

La economía popular y solidaria en el Ecuador tienen como objetivo mejorar las condiciones de vida, acceso al trabajo y el desarrollo de emprendimientos que dinamicen las economía locales, es decir, este modelo económico no tradicional se convierte en las alternativas de negocio sin fines de lucro que persigan el bienestar de las personas que integran este sector, por tal razón, el impacto de este modelo de acción colectiva a través del análisis del balance social debe plantearse desde una dimensión social, tal como propone RIBAS (2001), en la que considera aspectos no cuantificables de métodos ordinarios como el balance económico sino bajo una estructura que propicie el desarrollo del ser humano.

El Balance Social debe entenderse como un insumo y herramienta de gestión de la economía social y solidaria, sin caer en el error de realizar un análisis con sentido economicista y de información empresarial hacia la comunidad (Mugarra, 1995). Por su parte la SEPS (2013) en la metodología de balance social para el sector cooperativista enfatiza la caracterización de macro dimensiones y dimensiones que por su naturaleza y correspondencia con el sector económico popular y solidario obedecen a la relación entre los principios, valores y corresponsabilidad de una economía no tradicional, propuesta que concuerda con la OIT (2001) para definir indicadores del área interna y externa asegurando el análisis continuo y sistemático.

Cada país e incluso cada región y asociación tienen sus propias particularidades tanto en su funcionamiento, alcances y responsabilidades, relacionamiento interno y externo del núcleo asociativo como lo describe la Ley de Economía Popular y Solidaria y su Reglamento, por este motivo las propuestas metodológicas en el contexto internacional (propuestas no únicas pero con mayor orientación a la realidad ecuatoriana) mantienen una convergencia de distintas técnicas y aportes teóricos, aspectos que enriquecen a la propuesta de una metodología que caracterice al sector económico popular y solidario, pues como señala la SEPS (2013) es necesario contar con una metodología que vislumbre el balance social de la realidad del sector asociativo.

El sector asociativo de la economía popular y solidaria cumple con las funciones desde un ámbito social, debido principalmente a que éstas organizaciones buscan el bien común de sus asociados, considerando al ser humano como principio y fin de la actividad, criterios propuesto por la Asamblea Nacional del Ecuador (2011). Para analizar interna y externamente a este modelo asociativo la SEPS, (2014) propone un modelo de evaluación de balance social para el sector cooperativista del Ecuador, recomendando que es necesario identificar una metodología de evaluación del balance social hacia Ios demás sectores asociados que reconoce la LOEPS. Si bien la SEPS propone macro dimensiones y dimensiones, éstas no reflejan un sistema de indicadores que permita poner en perspectiva una 
metodología que cuantifique y cualifique los logros alcanzados desde lo social, en este caso, como señala la (OIT, 2001) los indicadores deben cumplir una serie de condiciones que aseguren la gestión empresarial, por lo que sería una metodología íntegramente aplicable a empresas de más de 20 empleados, coincidiendo con la propuesta de (DERES, 2013) que recomienda la aplicabilidad en la mediana empresa, ya que cuentan con información sustancial de las actividades logradas en el ejercicio económico anual; es así que estas propuestas se relacionan al caso ecuatoriano debido a que las asociaciones deben cumplir con un mínimo de 10 asociados.

El modelo asociativo del Ecuador, ante la necesidad de tomar una metodología apropiada para analizar los logros alcanzados en su núcleo asociativo y de emprendimiento, adoptan técnicas cuali cuantitativas que son aplicadas por empresas de capital sin tener una claridad en la perspectiva de economía popular y solidaria, para transformar esta realidad la metodología propuesta enfatiza el análisis de cada una de las macro dimensiones directamente relacionadas con el carácter social de las asociaciones de un modelo socio - económico, entre estas están: i) Prelación del trabajo sobre el capital y de los intereses colectivos sobre los individuales, ii) Asociación voluntaria, equitativa y respeto a la identidad cultural, iii) Autogestión y autonomía, Participación económica, solidaria y distribución equitativa de utilidades o excedente, iv) Educación, capacitación y comunicación, v) Comercio justo, comunidad, medio ambiente, y, vi) Acto económico solidario.

Por lo tanto, este sistema de macro dimensiones genera dimensiones e indicadores exclusivos para el sector asociativo de economía popular y solidaria convirtiéndose además en el insumo primordial en la rendición de cuentas de los actores sociales. Esta nueva propuesta pone en perspectiva una calificación cualitativa, cuantitativa y descriptiva de la acción social sin predominio del capital, sino en búsqueda de la equidad y equilibrio entre sus asociados.

\section{6.- Conclusiones}

La economía tradicional cuenta con una amplia gama de metodologías para evaluar distintos aspectos económicos y sociales, centrándose principalmente en los resultados y objetivos de acumulación económica y en cierta parte la corresponsabilidad del impacto que éstas generan en la sociedad a través de la Responsabilidad Social Empresarial, por el contrario, en el Ecuador se reconoce el modelo económico popular y solidario bajo el principio de el ser humano sobre el capital, y sobre éste el desarrollo del ámbito social. Este modelo económico, aún es nuevo, muestra de ello es la carencia de metodologías que permitan interpretar, conocer, ampliar, evaluar e investigar este sector, aspecto que permitió en la presente investigación desarrollar una metodología que evalúe desde un todo, el accionar, resultados y actuaciones de las asociaciones de economía popular y solidaria. 
Para definir las macro dimensiones y dimensiones que influyen en el sector asociativo, se analizó los contextos de la metodología planteada por la Superintendencia de la Economía Popular y Solidaria y otras (no únicas, pero con relación al ámbito social, comúnmente llamadas sectores no lucrativos), entre estas: Organización Internacional de Trabajo OIT, Desarrollo de la Responsabilidad Social DERES y Ribas M. Este proceso trajo como resultados un primer análisis de siete (7) macro dimensiones, veinte (20) dimensiones y treinta y nueve (39) indicadores que permiten desarrollar el análisis del Balance Social. Posteriormente a través de la aplicación de análisis de expertos, se evaluaron y validaron seis (6) macro dimensiones, diez y seis (16) dimensiones y treinta y dos (32) indicadores. Cada indicador contiene una fórmula de cálculo y las respectivas metas que fueron identificadas y sustentadas por la LOEPS y su Reglamento, el Estatuto y Reglamento interno de las asociaciones.

Metodológicamente, este proceso concluye con la construcción de un cuadro de análisis del Balance Social con el objetivo de sistematizar y brindar un valor a cada indicador obtenido; destacando que se convertiría en un proceso amigable y de fácil utilización para las asociaciones de economía popular y solidaria, ya que recoge la información de las encuestas y entrevistas que deberán desarrollarse tanto a la Asamblea General como al nivel administrativo de éstas asociaciones. Este modelo de balance social se presenta como un documento necesario para que las asociaciones cumplan con el rol y funciones de economía popular, bajo un criterio de principios, objetivos y normas de este modelo económico.

Finalmente ponemos en relevancia la aplicabilidad de la metodología propuesta en asociaciones de economía popular y solidaria del prestación de servicios de alimentación y limpieza, ya que son las que presentan una mayor representatividad económica y social en la Zona 2. Los resultados obtenidos en el balance social de las 3 asociaciones demuestran el grado de cumplimiento e impacto desarrollado a nivel interno y externo, convirtiéndose en el insumo para establecer estrategias y alternativas a mejorar sus condiciones sociales.

\section{Bibliografía}

ACCIÓN SOCIAL, ORGANIZACIÓN NO GUBERNAMENTAL (2012): Guía de evaluación de programas y proyectos sociales, Plataforma de ONG de Acción Social - España, Madrid.

ASAMBLEA NACIONAL CONSTITUYENTE DEL ECUADOR (2008): Constitución Política del Ecuador, Asamblea Nacional Constituyente del Ecuador, Quito.

ASAMBLEA NACIONAL DEL ECUADOR (2011): Ley Orgánica de la Economía Popular y Solidaria y del Sector Financiero Popular y Solidario, Corporación de Estudios y Publicaciones - Ecuador, Quito. 
ASTIGARRAGA, E. (2004): El método Delphi, Universidad de Deusto, Donostia - San Sebastian.

AUTROULAKIS, N. (2013): "Desafiando a la economía convencional: un paradigma ético del desarrollo. Problemas del Desarrollo", UNAM - México, Revista Latinoamericana de Economía, 44, 3353.

CARTES, F. (2015): Principios de evaluación de proyectos, CEPAL - Perú, Lima.

CECCHINI, S. (2005): Indicadores sociales en América Latina y el Caribe. Serie de estudios estadísticos y prospectivos, Naciones Unidas editorial, Santiago de Chile.

COLINA, J. \& SENIOR, A. (2008): "Balance Social. Instrumento de análisis para la gestión empresarial responsable", Multiciencias - Venezuela, Red de Revistas Científicas de América Latina y el Caribe, España y Portugal, 8, 71-77.

CORAGGIO, J.L. (2013a): "La economía social y solidaria ante la pobreza", Voces en el Fénix - Buenos Aires, La Revista del Plan Fénix, 22, 115-123.

CORAGGIO, J.L. (2013b): "La economía popular y solidaria en el Ecuador", Revista cooperativismo y desarrollo, Universidad Cooperativa de Colombia, 100, 272-280.

CORAGGIO, J.L. (2011): Economía Social y Solidaria: El trabajo antes que el capital, Ediciones Abya Yala, Quito.

DESARROLLO DE LA RESPONSABILIDAD SOCIAL (2013): Manual para la preparación e implementación del Balance Social en el Uruguay, Gráficas Pajón - Colombia, Medellín.

GIL, A. (2010): Tipos de indicadores para el balance social de la empresa, Ministerio de Trabajo y Asuntos Sociales España, Madrid.

HERNÁNDEZ. B. (2001): Técnicas estadísticas de investigación social, Editorial Díaz de Santos España, Madrid.

INSTITUTO NACIONAL DE ECONOMÍA POPULAR Y SOLIDARIA - DIRECCIÓN TÉCNICA ZONAL 2 (2016): Principales actores de la Zona 2, por sector. Montos de contratación pública y privada del sector de economía popular y solidaria a nivel nacional y zonal. Ecuador, Tena.

INSTITUTO NACIONAL DE ECONOMÍA POPULAR Y SOLIDARIA (2013): Rol de la Economía Popular y Solidaria y su aporte en el Sistema Económico Social y Solidario, IEPS - Ecuador, Quito.

JUBETO, Y., GURIDI, L. \& FERNÁNDEZ, M. (2014): Diálogos sobre economía social y solidaria en Ecuador. Encuentros y desencuentros con las propuestas para otra economía, Lankopi, S.A. Ecuador, Quito.

MUGARRA, A. (1995): Modelos de balance social: criterios clasificatorios, Universidad Deusto, Bilbao. Disponible en: http://miguelcm.unex.es/Lecturas\%20ASE/A\%20Mugarra,\%20Modelos\%20BS.pdf

ORGANIZACIÓN INTERNACIONAL DEL TRABAJO (2001): Manual de Balance Social, Gráficas Pajón - Colombia, Medellín. 
RIBAS, M. (2001): "El balance social como instrumento para la evaluación de la acción social en las entidades no lucrativas", CIRIEC-España, Revista de Economía Pública, Social y Cooperativa, 39, 115-147.

SECRETARÍA NACIONAL DE PLANIFICACIÓN Y DESARROLLO (2013a): Atlas de las desigualdades socioeconómicas del Ecuador, Senplades - Ecuador, Quito.

SECRETARÍA NACIONAL DE PLANIFICACIÓN Y DESARROLLO (2013b): Plan Nacional para el Buen Vivir 2013 - 2017, Senplades - Ecuador, Quito.

SUPERINTENDENCIA DE ECONOMÍA POPULAR Y SOLIDARIA (2016): Serie de Estudios sobre Economía Popular y Solidaria. Economía Solidaria. Historias y prácticas de su fortalecimiento, SEPS - Ecuador, Quito.

SUPERINTENDENCIA DE ECONOMÍA POPULAR Y SOLIDARIA (2014): Serie de Estudios sobre Economía Popular y Solidaria. Contextos de la "Otra Economía, SEPS - Ecuador, Quito.

SUPERINTENDENCIA DE ECONOMÍA POPULAR Y SOLIDARIA (2013): Estudios sobre la economía popular y solidaria, SEPS - Ecuador, Quito.

SUPERINTENDENCIA DE ECONOMÍA POPULAR Y SOLIDARIA (2012): "El Sector Económico Popular y Solidario", Boletín de Coyuntura, No. 1, SEPS - Ecuador, Quito.

\section{Anexos}

\section{Anexo 1. Definición de Macro dimensiones}

La definición de las seis (6) macro dimensiones que se establecen para la evaluación del Balance Social en la presente investigación, corresponde al análisis y empate de definiciones establecida por la SEPS, y lo determinado en la LOEPS y su Reglamento General:

Macro dimensión 1: Prelación del trabajo sobre el capital y de los intereses colectivos sobre los individuales

Las asociaciones del sector de la economía popular y solidaria fundamentan el principio de la Búsqueda del Buen Vivir y del bien común, teniendo al ser humano como principio y fin de la actividad. 
Macro dimensión 2: Asociación voluntaria, equitativa y respeto a la identidad cultural

Esta macro dimensión fundamente el principio en la igualdad, integración y cohesión social (identidad social), de modo que toda asociación no genera ningún tipo de discriminación, es decir, se garantiza la accesibilidad a la asociación, equidad de género y el conocimiento del sistema económico, social y solidario.

\section{Macro dimensión 3: Autogestión y autonomía}

Las asociaciones de forma democrática garantizan la autonomía a través del acceso a cargos administrativos y de gestión y control democrático de sus asociados, mientras que la autogestión se garantiza por el auto control y la relación con organizaciones del mismo sector económico, así como también las relaciones con el Estado.

Macro dimensión 4: Participación económica, solidaria y distribución equitativa de utilidades o excedente.

Tanto la participación económica, solidaria y distribución equitativa de utilidades son mecanismos democráticos en la participación del capital económico, en este sentido, la reinversión y utilización de utilidades tienen relación directa en la compensación social.

Macro dimensión 5: Educación, capacitación y comunicación.

Las asociaciones y el entorno en el que se desarrollan, no cuentan con procesos de formación académica entre sus asociados, por este motivo, las asociaciones considerarán programas de capacitación de sus asociados, asistencia técnica a sus emprendimientos y otros aportes que realicen tanto el sector público, privados, academia y ong's, de esta manera, la asociación asegurará la mejora continua y el desarrollo de las capacidades del talento humano.

Macro dimensión 6: Comercio justo, comunidad, medio ambiente y acto económico solidario

Siguiendo los principios de la economía popular y solidaria y del buen vivir, las asociaciones encaminarán a mejorar la calidad y mecanismos de comercialización de sus bienes y/o servicios, asegurando la participación de la población en donde se encuentran ubicados (se incluyen relaciones comerciales), fomentando políticas de cuidado y protección del medio ambiente y generando actos solidarios entre los asociados y la asociación. 


\section{Anexo 2. Definición de Dimensiones}

Las dieciséis (16) dimensiones que influyen de manera directa y sustancial al Balance Social son descritas tomando como referencia la definición establecida por la SEPS y lo aplicable al sector asociativo:

Macro dimensión: Prelación del trabajo sobre el capital y de los intereses colectivos sobre los individuales

Dimensión 1: Prelación del trabajo sobre el capital

Definición: Corresponde a la priorización del trabajo sobre la acumulación del capital. Esta dimensión medirá la economía del trabajo, es decir, de qué manera la asociación genera y distribuye el trabajo a sus asociados. (Coraggio, 2011b:33-41)

Dimensión 2: Prelación de los intereses colectivos sobre los individuales

Definición: Proyectará la medición de las actividades y montos invertidos por las asociaciones de la EPS dirigidas a promover el bienestar colectivo de sus miembros.

Macro dimensión: Asociación voluntaria, equitativa y respeto a la identidad cultural

Dimensión 3: Accesibilidad asociativa

Definición: Las organizaciones mantienen una actividad libre y voluntaria pero con responsabilidades.

Dimensión 4: Equidad de género

Definición: Comprenderá el peso porcentual de los socios y socias que conforman la asociación. Se deberá analizar, de existir, la diferencia de género en el grupo asociativo.

Dimensión 5: Conocimiento del sistema económico social y solidario por parte de los miembros

Definición: Se analizará el conocimiento previo de las personas que deciden asociarse, conociendo los principios, normas y reglamentos de la economía popular y solidaria, así como también del reglamento interno de la asociación.

\section{Macro dimensión: Autogestión y autonomía}

Dimensión 6: Acceso a cargos administrativos y de gestión

Definición: Los distintos integrantes de la asociación, tendrán las mismas facilidades y oportunidades de elegir y ser elegido para ocupar cargos administrativos y de gestión de acuerdo a su estructura interna. Los grupos minoritarios y de atención prioritaria tendrán mayor énfasis de acciones afirmativas para su participación, sin discriminación alguna. 
Dimensión 7: Control democrático por los socios

Definición: Autocontrol de la asociación, promovida por todos los socios y las comisiones que las integran. Participación en la fijación de políticas y directrices internas (reglamento interno) para la toma de decisiones de forma directa y/o representativa.

Dimensión 8: Acuerdos con otras organizaciones

Definición: Corresponde a los acuerdos, actas, convenios, entre otros acuerdos alcanzados entre cualquier forma de organización establecida en el sector de la economía popular y solidaria.

Dimensión 9: Relación con el Estado

Definición: Corresponde a los acuerdos, convenio o cualquier tipo de entendimiento para cofinanciamiento, asistencia técnica y cooperación con diferentes instituciones del sector público: Ministerios, Gobiernos Seccionales, Entidades de Control, etc.

Macro dimensión: Participación económica, solidaria y distribución equitativa de utilidades.

Dimensión 10: Utilización de utilidades

Definición: Se destinan al menos el 50\% (inversión), artículo 52 de la LOEPS.

Dimensión 11: Rendición de cuentas

Definición: Proceso mediante el cual la Junta Directiva cumplen su deber y responsabilidad de explicar, dar a conocer o responder a los asociados el manejo administrativo y económico de la asociación. La Junta de Vigilancia participa del informe presentado ante la Junta General. Tanto la Junta Directiva como la Junta de Vigilancia se reunirán en un los mínimos establecidos en los artículos 19 y 20 del Reglamento General de la Ley de Economía Popular y Solidaria.

Macro dimensión: Educación, capacitación y comunicación

Dimensión 12: Desarrollo de las capacidades de los actores relacionado a la asociación

Definición: Desde una visión integral de formación para los integrantes del grupo asociativo se considera las distintas participaciones y aprobaciones de cursos y talleres de formación promovidos por distintos sectores públicos, privados, ong, centros educativos, otros.

Macro dimensión: Comercio justo, comunidad, medio ambiente y acto económico solidario 
Dimensión 13: Comercio justo

Definición: También llamado comercio alternativo, se describe como las relaciones de intercambio comercial basadas en principios como: el diálogo, la transparencia, el respeto, la equidad en el comercio y el respeto a los derechos de los trabajadores, con precios justos, es decir, un desarrollo sostenible. En esta dimensión, se establecerán indicadores cualitativos y cuantitativos de acuerdo al cumplimiento de los principios y valores que definen el comercio justo.

Dimensión 14: Comunidad

Definición: Compromiso social con la comunidad (usuario externo) que realizan las asociaciones, se constituye por todas aquellas actividades para el beneficio general de la comunidad donde desarrollan sus actividades.

Dimensión 15: Medio ambiente

Definición: Las actividades que promuevan la protección del medio ambiente, a través de políticas de uso de recursos y su disposición final. Las actividades serán de acuerdo al lugar donde funcionan los emprendimientos de las asociaciones, identificando las particularidades de cada sector.

Dimensión 16: Acto económico solidario

Definición: Los actos económicos solidarios no corresponden a relaciones comerciales o civiles entre cualquier tipo de organización, sino, comprende las relaciones entre la asociación y sus miembros, a través de la realización de transacciones económicas (distribución, consumo o prestación de un servicio) internas de la asociación.

\section{Anexo 3. Indicadores}

Para definir cada indicador se toma en cuenta los aspectos clave de la definición de cada dimensión, de este proceso luego del análisis de expertos referido, se obtuvieron treinta y dos (32) indicadores que fueron priorizados para el análisis del Balance Social, de los cuales, se describen a continuación: 


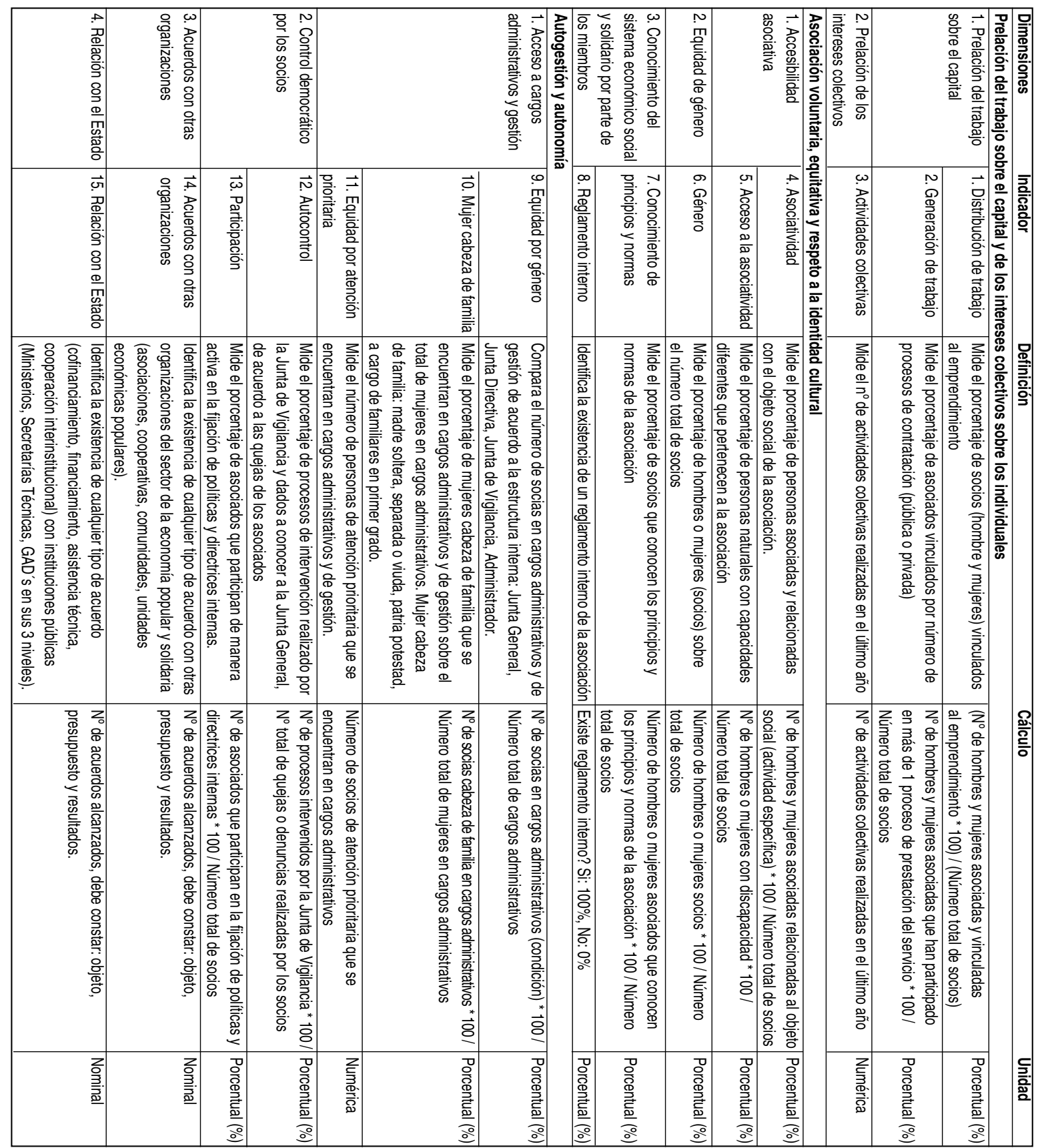




\begin{tabular}{|c|c|c|c|c|c|c|c|c|c|c|c|c|c|c|}
\hline 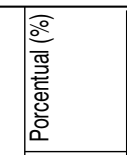 & 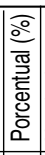 & 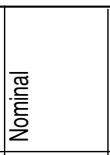 & 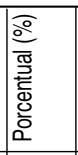 & 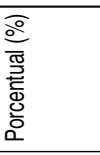 & & 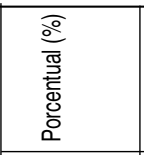 & 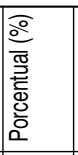 & 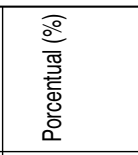 & 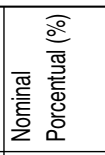 & & 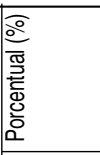 & 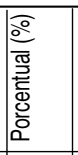 & 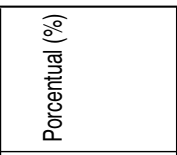 & 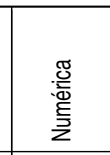 \\
\hline 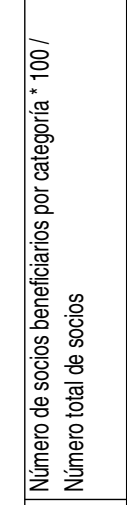 & 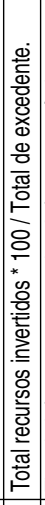 & 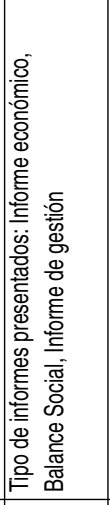 & 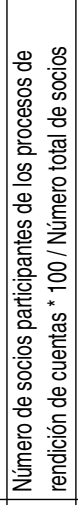 & 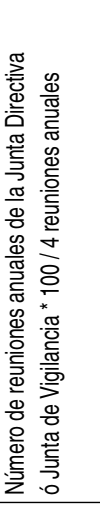 & & 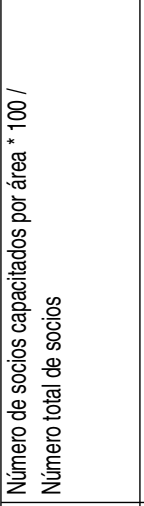 & 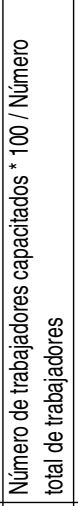 & 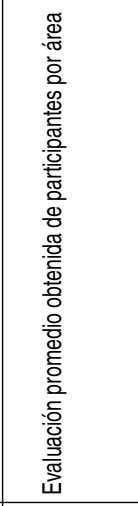 & 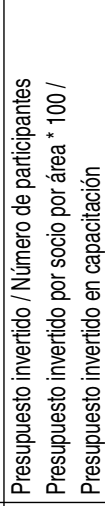 & & 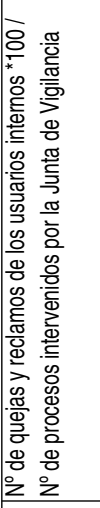 & 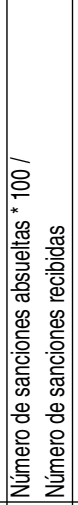 & 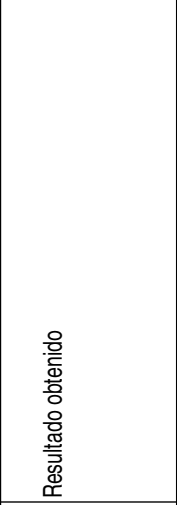 & 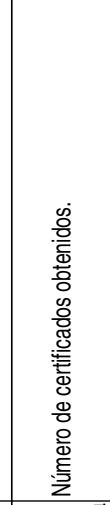 \\
\hline 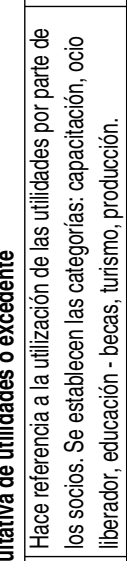 & 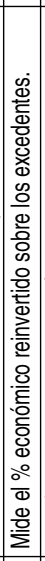 & 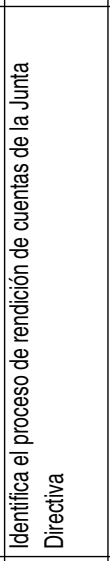 & 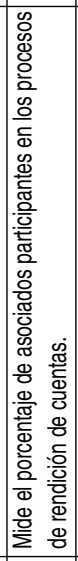 & 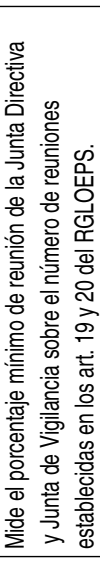 & & 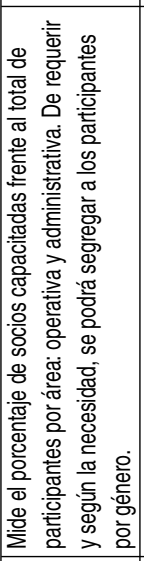 & 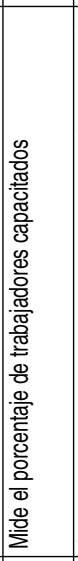 & 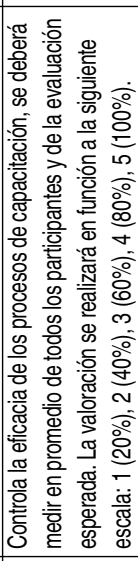 & 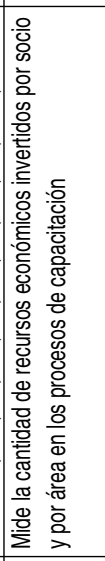 & 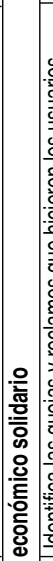 & 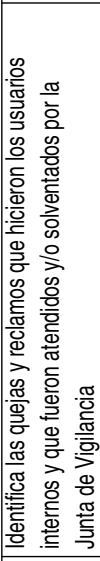 & 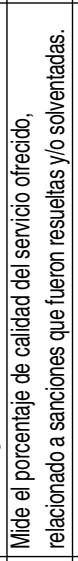 & 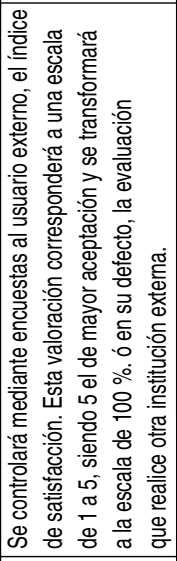 & 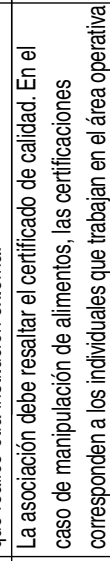 \\
\hline 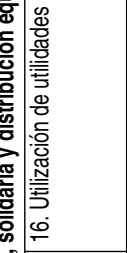 & 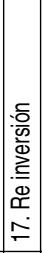 & 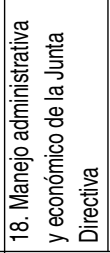 & 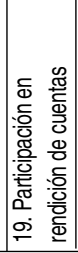 & 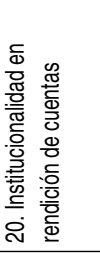 & 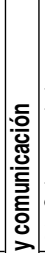 & 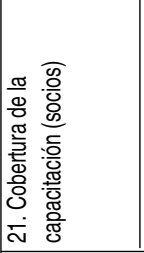 & 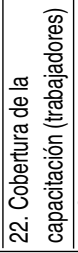 & 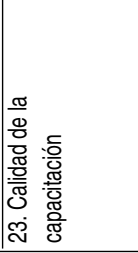 & 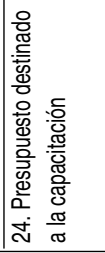 & 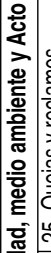 & 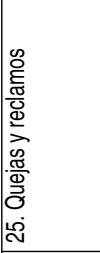 & 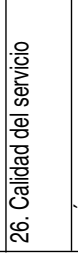 & 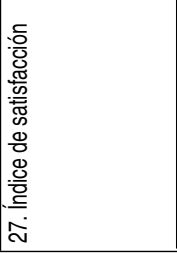 & 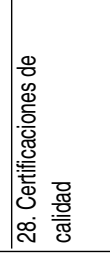 \\
\hline 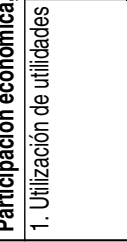 & & 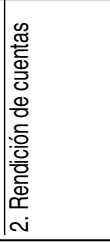 & & & & 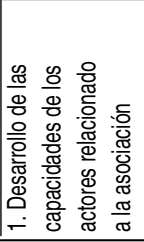 & & & & 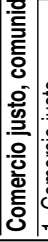 & . & & & \\
\hline
\end{tabular}




\begin{tabular}{|c|c|c|c|}
\hline 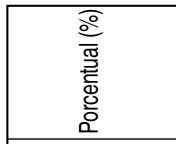 & 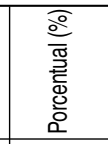 & 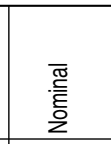 & 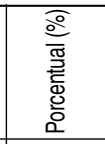 \\
\hline 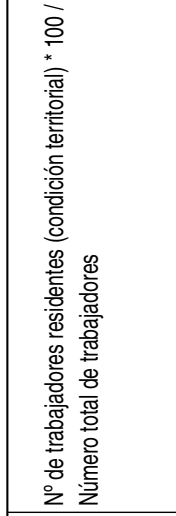 & 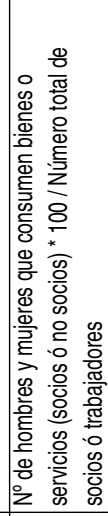 & 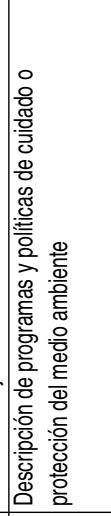 & 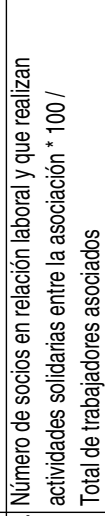 \\
\hline 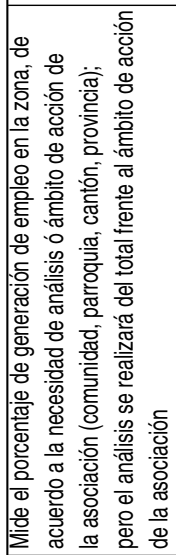 & 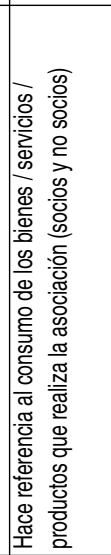 & 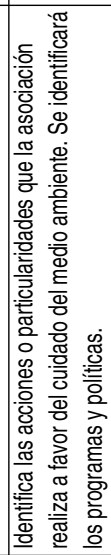 & 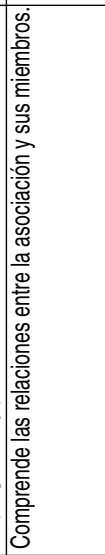 \\
\hline 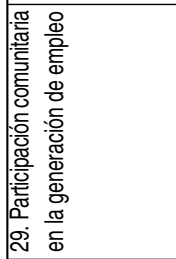 & 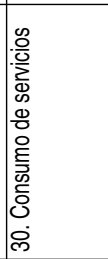 & 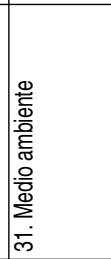 & 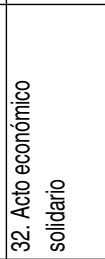 \\
\hline 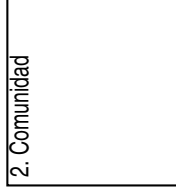 & & 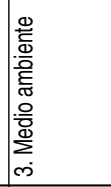 & 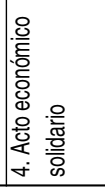 \\
\hline
\end{tabular}


